\title{
Ending an Elite Sports Career: Case Report of Behavioral Activation Applied as an Evidence- Based Intervention with a Former Olympic Athlete Developing Depression
}

Carolina Lundqvist

The self-archived postprint version of this journal article is available at Linköping University Institutional Repository (DiVA):

http:/ / urn.kb.se/ resolve?urn=urn:nbn:se:liu:diva-169313

N.B.: When citing this work, cite the original publication.

Lundqvist, C., (2020), Ending an Elite Sports Career: Case Report of Behavioral Activation Applied as an Evidence-Based Intervention with a Former Olympic Athlete Developing Depression, The Sport psychologist. https:// doi.org/ 10.1123/ tsp.2019-0152

Original publication available at:

https:// doi.org/ 10.1123/ tsp.2019-0152

Copyright: Human Kinetics

http:// www.humankinetics.com/ europe 
As accepted for publication in The Sport Psychologist, (C) Human Kinetics, https://doi.org/10.1123/tsp.2019-0152

(Accepted: $31^{\text {th }}$ July 2020)

\title{
Ending an Elite Sports Career:
}

\section{Case Report of Behavioral Activation Applied as an Evidence-Based Intervention with a Former Olympic Athlete Developing Depression}

\author{
Carolina Lundqvist \\ The Swedish Olympic Committee \\ Department of Behavioural Sciences and Learning, Linköping University, Sweden. \\ ORCID-id: 0000-0001-6570-5480 \\ Corresponding author: Carolina Lundqvist, Department of Behavioural Sciences and \\ Learning, Linköping University, 58183 Linköping, Sweden. E-mail: \\ carolina.lundqvist@liu.se.
}

\section{Acknowledgment}

Thanks to the former Olympic athlete who generously agreed to share information and thereby help to disseminate the use of evidence-based treatments to practitioners in the field of applied sport psychology. 


\title{
APPLYING BEHAVIORAL ACTIVATION IN ELITE SPORTS
}

\begin{abstract}
This case report describes the use of behavioral activation (Martell et al., 2010) when a former Olympic athlete developed depression after career termination. Four sessions were conducted, one session each week, followed by a boost session one month later. In Session 1, the former Olympic athlete displayed mild to moderate depression with anxiety and a low quality-of-life (MADRS-S = 21; GAD-7 = 17; BBQ = 44). By Session 3, the Olympic athlete no longer met the diagnostic criteria for clinical depression or anxiety (MADRS-S = 2; GAD$7=7)$ and quality-of-life was improved $(\mathrm{BBQ}=60)$. Follow-up assessments one year posttreatment confirmed that the former Olympic athlete continued to improve (MADRS-S = 0; GAD-7 = 0; BBQ = 96). This case report discusses the benefits of proactive support to elite athletes and the use of established clinical psychological treatments, for example behavioral activation, when athletes develop health-related conditions.
\end{abstract}

Keywords: behavioral activation, career transition, depression, elite athlete, mental health 


\section{APPLYING BEHAVIORAL ACTIVATION IN ELITE SPORTS}

At some point, elite athletes will undoubtedly find themselves in the situation when the active elite career is finished. Career termination is one of the various naturally occurring transition phases elite athletes encounter, and career transitions often affect several parts of life at different levels (e.g., the athletic level, psychological level, psychosocial level, academic and vocational level; Wylleman, Alferman, \& Lavallee, 2004). Many elite athletes manage career retirements without significant concerns. However, research also shows interindividual variability in reactions, where some athletes experience career transition challenges with diverse degrees of psychological symptom severity and psychosocial difficulties (e.g., Knights, Sherry \& Ruddock-Hudson, 2016; Park, Lavallee, \& Tod, 2013). These challenges may, for example, consist of a loss of identity, adjustment difficulties to a new life, economic struggles, and adverse emotional reactions (Knights et al., 2016; Martin, Fogarty, \& Albion, 2013; Park et al., 2013; Stambulova, Alfermann, Statler, \& Coté, 2009). Also the network with close social relationships around the athlete, which is generally regarded as an essential and protective support system for the athlete during transition phases (e.g., Eggleston, Hawkins, \& Fife, 2019), may be affected by the network members’ own adjustment difficulties because of changed social dynamics which may decrease their capacity to provide adequate support (Brown, Webb, Robinson, Cotgreave, 2019).

Minor adjustment reactions are common close to the time of career termination. Athletes going through voluntary and prepared elite sport termination commonly express minor initial concerns that generally are naturally decreasing over time (Martin et al., 2013; Park et al., 2013; Torregrosa, Ramis, Pallarés, Azócar, \& Selva, 2015). Aversive and more severe psychological reactions to career retirements (e.g., depressive conditions) have often been associated with involuntary reasons for retirement, for example, career-ending injuries (Lavallee, Gordon, \& Grove, 1997; Martin et al., 2013; Park et al., 2013; Sanders \& Stevinson, 2017). While both qualitative and quantitative studies inevitably have increased the 


\section{APPLYING BEHAVIORAL ACTIVATION IN ELITE SPORTS}

knowledge and awareness of various psychosocial challenges that retiring elite athletes may experience, there is still a lack of published information and detailed examples of available clinical treatments to support elite athletes during and after the critical career termination phase when they are confronting various psychological health-related issues. The present case report, therefore, describes a psychological support intervention, which is an evidence-based clinical psychological treatment, delivered to a retiring Olympic athlete who developed depression after career termination.

\section{The Heterogeneous Nature of Depression}

The label depression is commonly adopted in literature to describe conditions representing a mixture of individual experiences varying in severity and idiographic content (Doherty, Hannigan, \& Campbell; Lebrun, MacNamara, Rodgers, \& Collins, 2018; Maj, 2011; Martell, 2013; Paris, 2015; Wakefield \& Schmitz, 2013). Based on evolutionary theories of emotions, sadness and low mood may not only be a sign of psychopathology but may also be expressed when emotional responses to adversity are healthy and adaptive, whereby clinical depression from this perspective is suggested to represent a prolonged and dysregulated condition of mood (Hagen, 2011).

The Diagnostic and Statistical Manual of Mental Disorders-5 (DSM-5; American Psychiatric Association, 2013a), which is an auxiliary tool in the diagnostic process of psychological disorders, provides symptom-based diagnostic criteria for clinical depression. Criteria in DSM-5 require at least five of the nine listed depressive symptoms, including markedly diminished pleasure/feeling down or loss of interest or enjoyment in usual activities, to be present most of the time during a minimum of two weeks. The symptoms should also cause distress of clinical significance or impaired function in essential life-areas, for example socially or at work, but should not be related to the physical effects of other medical conditions or drugs (DSM-5; American Psychiatric Association, 2013a). The symptom-based 


\section{APPLYING BEHAVIORAL ACTIVATION IN ELITE SPORTS}

DSM-5 criteria of depression is nevertheless argued to display questionable validity and empirical support (e.g., Paris, 2015), which may pose a risk of false positives meaning that psychiatrically healthy individuals falsely could be classified as clinically depressed (Paris, 2015; Wakefield, 2015; Wakefield \& Schmitz, 2013; Wakefield, Schmitz, \& Baer, 2010). When performing clinical interviews and consulting the DSM-5 criteria, the clinician should therefore carefully consider that individuals' reactions to normal life-stresses can produce transient non-clinical depressive symptoms similar to, and easily confused with, a pathological state of depression (e.g., Maj, 2011; Paris, 2015).

\section{Stressful Life Events and Depression}

Most people overcome stressful life-situations without developing pathological conditions, but major stressful life events are known as a general risk-situation for the onset of clinical depression (e.g., Hagen, 2011; Hammen, 2015; Martell et al., 2010). Also in the sport psychology literature, the association between various challenging phases or situations during the elite sports career (e.g., career transitions, injuries, life stress, performance setbacks or failures, post-Olympic experiences, stressors in the team or sports organization) and psychological symptoms linked to a depressive mood have been acknowledged (e.g., Beable, Fulcher, Lee, \& Hamilton, 2017; Doherty et al., 2016; Howells \& Lucassen, 2018; Lebrun et al., 2018; Lundqvist \& Gustafsson, 2020; Nixdorf, Frank, \& Beckmann, 2015; Ströhle, 2019; Wolani, Gross, \& Hong, 2015). Golding, Gillingham, and Perera (2020) found that the prevalence rates varied from $7 \%$ to $34 \%$ across studies investigating depressive symptoms among elite athletes. The prevalence of self-reported symptoms associated with anxiety and depression among former elite athletes has been estimated to 26\% (Gouttebarge et al., 2019). A career termination generally causes a rather extensive life-change for an elite athlete because this situation may result in major alterations in lifestyle, daily routines and also the need for new goals and values in life (e.g., Lavallee et al., 1997; Stephan, Bilard, Ninot, \& 


\section{APPLYING BEHAVIORAL ACTIVATION IN ELITE SPORTS}

Deligniéres, 2003). Thus, career termination in general is a risk factor for depressive conditions to develop among elite athletes.

The association between major life events and depression is today considered to be complex and bidirectional with numerous plausible psychosocial moderators. For example, demographic factors, stressful childhood experiences, personal clinical history of prior depression, ruminative response-style, personality dispositions, dysfunctional informationprocessing and various biological mechanisms (e.g., genetics, hypothalamic-pituitary-adrenal axis response, hormones, brain function) are known to interact at various levels (Hammen, 2015). From an applied and clinical perspective, the complex relationship between life events and depression emphasizes the need for research-informed clinical training, judgment, and experience and to carefully consider various predisposing and maintaining factors as well as contextual factors and individual resources in each case.

\section{Psychological Treatments of Depression: Behavioral Activation}

Evidence-based psychological treatments for depression are today available in medical care (e.g., American Psychological Association Division 12, 2020; National Institute for Health \& Clinical Excellence, 2010). Psychological treatments that are acknowledged to have strong research support include, for example, cognitive therapy (often referred to as cognitivebehavioral therapy), interpersonal therapy, and behavioral activation (e.g., American Psychological Association Division 12, 2020). Whereas Beck's cognitive therapy over the years has received extensive empirical research support as a psychosocial treatment for depression (Beck, 2019), the magnitude of its efficacy has also been discussed (Johnsen \& Friborg, 2015; Waltman, Creed, \& Beck, 2016). Component analyses and randomized controlled studies suggest that the behavioral activation component in particular explains the efficacy of cognitive therapy treatment (Dimidjian et al., 2006; Jacobson et al., 1996). 


\section{APPLYING BEHAVIORAL ACTIVATION IN ELITE SPORTS}

Behavioral activation (BA) is an evidence-based, structured, individualized, and timelimited psychological treatment intervention, which focuses directly on behavioral change (Dimidjian, Barrera, Martell, Munoz, \& Lewinsohn, 2011). One of the critical principles of BA is that changing what the client does, in small steps, will also change the client's mood. The therapist takes on the role of a collaborating coach during the process, for example provides encouragement and structure, makes suggestions, educates and helps with planning and problem-solving (Martell et al., 2010). The therapy aims primarily to (a) increase engagement in rewarding behaviors and activities, (b) decrease avoidance behaviors or the person's engagement in those activities that act to increase or maintain the depressive condition, and to (c) use problem-solving related to factors that hinder the person from getting in contact with rewarding activities or maintain avoidance behaviors (Dimidjian et al., 2011).

The clinical BA-model for depression (Martell et al., 2001, 2010) suggests that life events, for example various losses, conflicts or a changed family situation, may sometimes decrease the person's contact with various positive reinforcers in life. Subsequently, negative affective symptoms such as "feeling blue”, sad and tired may increase. In an attempt to avoid these negative experiences, the person might also narrow the behavioral repertoire. Common short-term ("in the moment") behavioral responses to try to decrease the impact of negative affect include becoming more passive in life and using various avoidance behaviors to avoid emotional distress. For example, a person might avoid social interactions and choose to stay at home alone ruminating which may increase the risk of getting trapped in a vicious circle where depressive symptoms get even worse because of reduced contact with positive reinforcers in the environment (Martell et al., 2010).

BA is a process-oriented intervention which is performed collaboratively and guided by theory and functional analyses where the client is supported to structure and plan rewarding activities in line with life goals and values, rather than to act according to their occasional 


\section{APPLYING BEHAVIORAL ACTIVATION IN ELITE SPORTS}

moods. Moreover, BA is not a talking therapy. The therapist instead supports the client to become more activated behaviorally and engaged in behaviors related to positive reinforcement in the person's environment which subsequently increase the quality-of-life (Martell, 2018; Martell et al., 2001, 2010). Various behavioral tools (e.g., self-monitoring, problem-solving, activity scheduling, shaping, problem-solving, reinforcement, social skills training) are also used in BA with a high degree of flexibility (Dimidjian et al., 2011; Martell, 2013).

Purpose. This case report demonstrates the applications of BA, an evidence-based treatment, to an Olympic athlete who developed depression after career termination. The entire process from initial contact to completion of treatment and the evaluation of treatment outcomes is described. An advantage of authentic case reports is that detailed process-based information, including self-assessments, is collected continuously as an integrated part in the treatment which decreases memory biases that may occur when athletes are asked to recall in retrospect.

\section{Case Report}

\section{Ethical Considerations}

The former elite athlete described in this case report has provided informed consent regarding the publication of this article, including self-assessments and other work materials

used. All personal information (e.g., gender, age, sport) has been omitted or slightly changed to protect the athlete’s anonymity. "Foa” is used as a pseudonym (i.e., Former Olympic Athlete) instead of the athlete's real name and the practice during the intervention followed the code of ethics for the profession of psychotherapists in Sweden.

\section{Psychological Treatment with Behavioral Activation}




\section{APPLYING BEHAVIORAL ACTIVATION IN ELITE SPORTS}

Session 1: Clinical interview, self-assessments, and psychoeducation. Foa contacted the author to get psychological support because she was experiencing emotional difficulties after career termination. The author of this article (a) has a PhD. in Psychology and is an Associate Professor in Sport Sciences, (b) is a clinical psychotherapist licensed by the Swedish National Board of Health and Welfare and is thereby qualified to practice as a clinical psychotherapist in the Swedish health care system, and (c) has extensive applied experience of providing psychological support to Olympic athletes. The author performed the clinical interview, the case formulation and the subsequent BA treatment with Foa.

Using established procedures of cognitive-behavioral case formulations, in which both comorbidity and differential diagnostics are considered (cf. Corrie, Townend, \& Cockx, 2015; Kuyken, Padesky, \& Dudley, 2011; Persons \& Tompkins, 2006), Foa was asked about her clinical and life history, social networks, present situation, and various symptoms. She had experienced a long career at an Olympic level and had participated successfully at several Olympic Games. The decision to end the elite sports career was fully self-chosen. Socially, Foa had good access to social networks and social support, among all, a romantic partner, relatives, and many close friends. Foa described a low level of functioning in everyday life that had affected her considerably during the last three weeks. She experienced almost no enjoyment, a lack of energy, and almost no interest in taking part in everyday activities or socializing with her partner or friends. She worried considerably, experienced difficulties concentrating and continually noticed diffuse and unusual symptoms in her body. Moreover, Foa experienced guilt for not being happy. A prior medical consultation (e.g., blood samples and physical examinations by a medical doctor) had not revealed any physical explanation for her symptoms.

Foa completed several validated and established clinical self-rating scales commonly used in Swedish health-care: (a) the Montgomery Asberg depression rating scale (MADRS-S; 


\section{APPLYING BEHAVIORAL ACTIVATION IN ELITE SPORTS}

Montgomery \& Åsberg, 1979; Svanborg \& Åsberg, 2001), (b) the Generalized anxiety disorder-7 assessment (GAD-7; Spitzer, Kroenke, Williams, \& Löwe, 2006), (c) the Brunnsviken brief quality of life scale (BBQ; Lindner et al., 2016) and (d) the DSM-5 selfrated level 1 cross-cutting symptom measure (DSM-5 Self-Rated CCSM; American Psychiatric Association, 2013b). Table 1 shows a summary of the scales and guidelines for clinical evaluation. Figure 1 shows Foa's self-ratings of the assessments: MADRS-S $=21$ (indicating likelihood of moderate depression), GAD-7 = 17 (indicating severe anxiety) and $\mathrm{BBQ}=44$ (indicating relatively low quality-of-life). Scores of the DSM-5 self-rated CCSM showed that Foa rated items related to depression, anger, anxiety, somatic symptoms, and personality functioning with higher scores (i.e., $\geq 2$ ), and these items were therefore followedup with questions. In addition to self-report assessments, a suicide risk evaluation was performed (e.g., Osorno, Svanström, \& Beskow, 2010) with no risk of suicide detected at the time of assessment. The information derived from the clinical interview and the selfassessments, which was summarized in the case formulation, confirmed that Foa met criteria according to DSM-5 for mild to moderate clinical depression (primary diagnosis), and that the depressive condition was accompanied with symptoms of moderate anxiety but not an anxiety disorder (American Psychiatric Association, 2013a).

Psychoeducation. Foa received psychoeducation regarding the condition of clinical depression and was informed about available evidence-based treatments. Foa wanted to begin with psychotherapy because she wanted to learn tools and strategies to help her in current and future situations. Because the clinical interview revealed that a specific life event (i.e., the career termination) had triggered the onset of Foa's depression, and she had no previous history of clinical depression, BA was considered an appropriate treatment alternative. The rationale for BA and the clinical model (Martell et al., 2010) were presented to Foa who expressed a high degree of recognition of her behavioral pattern and agreed to start with BA 


\section{APPLYING BEHAVIORAL ACTIVATION IN ELITE SPORTS}

as treatment. A guide on how to apply the clinical model when working with clients is available as part of the clinician's guide by Martell and colleagues (2010). In Foa's case, the rewarding activities and behaviors she previously had as an elite athlete had decreased considerably. Subsequently, aversive emotions increased, and she had become passive in life and had also reduced her training volume. Because of her depressive mood, she used several avoidance behaviors. For example, she frequently stayed at home instead of engaging in social activities which she previously enjoyed.

Homework. BA is a highly individualized and flexible treatment where the therapist analyzes how to adapt the treatment to the individual, assesses what factors that act to maintain the depression, and identifies factors that can lead to improvement (Dimidjian et al., 2011; Martell, 2018). The therapist and the client together determine the homework to be carried out in the client's everyday life between sessions. The first homework task aimed to obtain a better understanding of Foa's specific behavioral patterns. Thus, Foa was instructed to use a diary to monitor all activities she did each day during a week and to rate mood states (neutral, positive, negative) associated with these activities. Activity monitoring is one of the primary tools the therapist uses to assess specific behaviors in BA (Martell et al., 2010).

\section{Session 2: Behavioral analyses, values in life and treatment goals. All sessions} started with Foa completing self-assessments (i.e., the MADRS-S, GAD-7, and BBQ). Foa's self-rated scores at session 2 indicated that her depression and anxiety had decreased (MADRS-S = 14; GAD-7 = 12) but also had her self-rated quality-of-life (BBQ = 32).

Analysing specific behaviors. Foa had monitored her activities during the week. Foa's activity monitoring displayed that many activities she engaged in were associated with a negative mood. Moreover, the function of these behaviors was commonly to avoid or get rid of momentary anxiety perceived during the days. For example, when feeling anxious, she over engaged in various work-related projects or activated herself covertly by ruminating 


\section{APPLYING BEHAVIORAL ACTIVATION IN ELITE SPORTS}

about her life or various symptoms perceived. Foa also over engaged in mindfulness exercises during the days because she had heard that mindfulness could be helpful when not feeling well. However, the mindfulness exercises were time-consuming. They also increased her feelings of loneliness because they caused her to stay at home alone, focusing on feelings of her decreased well-being rather than leaving her house to socialize with friends and engage in activities she usually enjoyed. Overall, these behaviors had the function of decreasing her momentary anxiety but in the long run maintained or increased her depressive mood and anxiety (cf. Martell et al. 2010; Sundel \& Sundel, 2017). Moreover, these behaviors decreased the likelihood of her spending time engaging in activities that could improve her well-being (i.e., “antidepressant” behaviors and activities; Martell et al., 2010).

Values and individual treatment goals. When using BA, the therapist supports the client in identifying individual treatment goals for improvement in line with life goals and values (Martell et al., 2010). After career termination, Foa had never paused to reflect on values in her new life outside elite sport. As a former elite athlete, Foa was highly performance-oriented with her identity and inner values still highly related to achievements. For example, she had difficulty in understanding the meaning of "leisure”, and she lacked experience in taking part in activities without the need for a flawless performance. In line with the BA-guidelines (Martell et al., 2010), the principles from the Acceptance and Commitment Therapy (ACT; Hayes, Strosahl, \& Wilson, 2012) literature were adopted to identify and discuss values with Foa. Foa identified friendship and staying healthy as highly valued, together with a wish to inspire others (e.g., giving lectures about her experiences of elitesport).

Most of the activities and behaviors Foa had monitored during the last week were not in line with her values. For example, Foa spent almost no time on well-being stimulating activities performed for non-performance purposes. Her schedule for each day was inflexible, 


\section{APPLYING BEHAVIORAL ACTIVATION IN ELITE SPORTS}

increasing her anxiety when she could not spontaneously change her plans even if opportunities for fun and rewarding activities were presented. Foa also spent little time with friends. Moreover, she had difficulty maintaining regular daily routines and never took time to pause or reflect on her life-balance.

In the next phase, individual treatment goals were formulated based on analyses of Foa's behaviors, her life-values and the general BA principles (Martell et al., 2010). Foa’s individual treatment-goals were formulated as: I should be able to (a) Schedule my days so there is room for spontaneity (not crowded days) and be able to change plans as needed, (b) Meet another person every day and shift focus outwards (instead of ruminating), (c) Tune into my life in a way that is balanced based on what I value as important in my life. When asked to rate her current ability to perform these goals on a scale between "cannot do this at all” (0) to “I am brilliant at doing this” (10), Foa rated all treatment goals as zero.

Activity scheduling. The final phase of the session was to identify minor naturally rewarding activities that Foa could start engaging in during the next week (e.g., meet a friend, perform low-intensity physical exercise for health-related purposes, spend time on writing which she previously had enjoyed). These activities were also scheduled. This step followed the fundamental principle for BA, viewing behavioral change as the primary mechanism for mood change. Thus, instead of getting trapped and letting momentary emotional states dictate her behaviors, Foa was encouraged to engage in scheduled rewarding activities even if she experienced sudden aversive emotions (cf. Martell, Addis, Jacobson, 2001; Martell et al., 2010). Together with Foa, a few, but not too many, rewarding activities (e.g., meet a friend) were scheduled each day for the next week. Problem-solving was used to anticipate and solve any obstacles that could hinder her from performing rewarding activities. As homework for the next week, Foa agreed to continue the activity scheduling and activity monitoring each day. She received information that she could change her planning if she noticed in advance 


\section{APPLYING BEHAVIORAL ACTIVATION IN ELITE SPORTS}

that it was not sustainable or any adjustments were necessary. However, she should not cancel rewarding activities because of sudden aversive emotions. Moreover, she was advised to take time to reflect on her life balance to make sure she did not schedule too many activities each day and that the balance between work and recovery was appropriate.

\section{Session 3: Early treatment response and sudden gains. In session 3, Foa} described her mood as considerably improved. Her self-ratings confirmed her subjective experience, where she no longer scored above cut-off levels for depression (MADRS-S = 2) or anxiety (GAD-7 = 7). Her scores also indicated a clinically significant improvement in quality-of-life $(\mathrm{BBQ}=60)$. The clinical evaluation based on Foa's descriptions and her selfratings was that Foa no longer met the diagnostic criteria for clinical depression, which indicated that Foa displayed an early response and sudden gains (i.e., a sudden decrease in depression scores was observed between two subsequent sessions) from the treatment. The association between an early response to therapy and a positive outcome post-treatment is established by numerous research studies (e.g., Beard, \& Delgadillo, 2019; Lutz, Stulz, \& Köck, 2009) and sudden gains are known as a relatively frequently occurring phenomenon (e.g., Tang, DuRubeis, Hollon, Amsterdam, \& Shelton, 2007). Sudden gains are, in similarity with the early response, a good predictor for stable treatment results when BA is adopted (e.g., Masterson et al., 2014; Singla, Hollon, Fairburn, Dimidjian, \& Patel, 2019) whereby the prognosis for Foa's treatment results was judged as good.

The next phase of the session focused on reviewing and reflecting on the homework performed during the last week, where Foa showed a commitment to and an understanding of how she could use the behavioral principles of BA to regulate her mood. During the last part of the session, Foa's romantic partner participated and was educated about depression and BA to be able to support Foa. By involving her partner and providing the partner with knowledge and tools to help Foa, Foa's social support in her ordinary life was strengthened. 


\section{APPLYING BEHAVIORAL ACTIVATION IN ELITE SPORTS}

Collaboratively it was decided that in Foa's homework she would continue to practice her BA-skills and also involve her partner in the process.

Session 4, boost session and one-year follow-up assessments. In session 4, Foa was smiling and relaxed when she described she was now feeling well and experienced a high quality-of-life. Her self-ratings confirmed her description (MADRS-S = 6; GAD-7 = 6; BBQ $=68$ ). Foa's ratings of the progress of her individual treatment goals, displayed in Table 2 , showed she had improved considerably but that there was room for further improvement. Because the treatment results obtained at this stage showed a favorable prognosis, the therapist in conjunction with Foa decided to prepare for ending the treatment.

Relapse prevention. A maintenance plan is an essential therapeutic tool to help prevent relapse post-treatment (Butler, Fennell, \& Hackmann, 2008; Martell et al., 2010). It is a written plan developed with the client to support the client in remembering lessons learned from working with BA. Thus, together with Foa, individual situations or circumstances that could make her vulnerable to depression, factors that had acted to maintain her depressive condition, her behaviors that acted as antidepressants, and her learned strategies to increase the probability of continuing antidepressant behaviors were written down. Foa was encouraged to read the maintenance plan regularly to remind herself of the content of the therapy and her strategies.

To make sure Foa's well-being remained stable or improved and to remind Foa to use the BA-principles, a final session (a "boost session”) was scheduled one month later. The somewhat prolonged time until the boost session also allowed Foa to start practicing the techniques more independently and to rely on available sources of support in her ordinary life (e.g., her partner). Foa was informed that she could contact the therapist if her well-being decreased. As shown in Figure 1, Foa's self-ratings confirmed that her well-being remained stable also at the boost-session, when the formal BA-treatment had ended (Boost session: 


\section{APPLYING BEHAVIORAL ACTIVATION IN ELITE SPORTS}

MADRS-S = 5; GAD-7 = 5; BBQ = 84). Moreover, post-treatment she continued to improve which was confirmed by Foa's self-assessments collected one-year later (MADRS-S = 0; GAD-7 = 0; BBQ = 96; DSM-5 self-rated CCSM = 0 on all items).

\section{General Discussion}

The present case report provided an applied example of behavioral activation (BA) as an available treatment option when an elite athlete developed depression after career termination. Although elite athletes perform extraordinary athletic achievements in the sporting arena, they are human and therefore respond to significant life events as humans. Fortunately, a high number of psychological treatments for various conditions (e.g., American Psychological Association Division 12, 2020; Barlow, 2014) are currently available in the clinical literature and are acknowledged to have strong research support in terms of their efficacy (studied by randomized controlled trials) and their effectiveness (studied by pragmatic trials in clinical settings). As was demonstrated in this case report, BA focuses primarily on increasing the client's psychosocial functioning with behavioral change and thereby helps the client to increase quality-of-life. Importantly, its full application in clinical cases requires the practitioner to possess adequate clinical knowledge, experience, and therapeutic competence together with a thorough understanding of the principles, theory and behavioral analyses that guide the BA-treatment. BA is nevertheless rather simple to learn for psychotherapists who are trained in various therapeutic approaches, and all principles underlying the treatment are described in the treatment manual (Martell et al., 2010).

One single psychological treatment will, however, not be the solution for all athletes or individual circumstances, whereby various options should be considered based on the needs and individual characteristics of each athlete. Ultimately, support provision is dependent on a combination of available scientific support for different interventions, the practitioner's assessment and judgment of the individual case, and the athlete's preferences regarding 


\section{APPLYING BEHAVIORAL ACTIVATION IN ELITE SPORTS}

support. Sport psychology research has found that minor adjustment difficulties and emotional reactions related to career termination can spontaneously improve over time (Park et al., 2013), suggesting that formal psychological support provision is not always necessary for recovery. Spontaneous recovery is also common for mild to moderate depression in general. For example, Whitford and colleagues (2013) reported in a systematic review and meta-analysis that 23\%, 32\% and 53\% of depressed participants spontaneously recovered from mild to moderate depression without treatment within 3, 6 and 12 months, respectively. Spontaneous remission decreased nevertheless with increased depression severity. In the present case of Foa, who suffered from mild to moderate depression, it cannot be ruled out that she would have recovered spontaneously over time without treatment. The course of her depression and the coincidence of sudden gains with her conscious efforts to change behavior make it likely, however, that the treatment was of great benefit for her at the stage of the depression she was in at the time.

In the clinical literature, continuous and stage models of depression are gaining increased popularity because of their clinical utility, where attempts are made to align the level of support with the severity of the condition (e.g., Maj, 2011; Patel, 2017). These models may, for example, suggest that clinical conditions of increased severity should be supported by evidence-based psychological treatments and/or antidepressant medication, and that nonclinical life distress should be supported by preventive efforts (e.g., proactive self-care and low-intensity support from close relationships; Patel, 2017). Career termination and other common obstacles or significant stressors that elite athletes may confront (e.g., sport injuries, performance setbacks, life or sport-related stressors) which involve life-changes are currently well-known to be risks for the development of depressive conditions among athletes (e.g., Appaneal, Levine, Perna, \& Roh, 2009; Lundqvist \& Gustafsson, 2020; Park et al., 2013; Wolanin et al., 2015). The knowledge of common risk-situations for depression among 


\section{APPLYING BEHAVIORAL ACTIVATION IN ELITE SPORTS}

athletes provides good opportunities to anticipate problems and therefore to deliver lowintensity preventive support before problems or clinical issues arise.

Coaches, staff or other significant people in the athletes’ regular environment, who are working closely with athletes and know them well, are often in a good position to provide proactive general support to help to stimulate meaningful activities for the athletes. These activities might therefore also increase various "antidepressive behaviors" when athletes confront risk-situations linked to an individual's increased vulnerability for depressive conditions. Simple but useful strategies that coaches and other significant persons around athletes can use in such risk-situations are, for example, to encourage athletes to stay in contact and spend time with team members and other friends, and to help athletes find out and arrange viable and alternative activities that are perceived as gratifying. For example, athletes who cannot practice fully may find it meaningful to contribute in a leadership role during training sessions, act as a role model or mentor for younger athletes or to take the opportunity to spend time with good friends they previously could not prioritize due to tight training and competition schedules. Essential components of proactive support for athletes who have experienced overall life changes include helping them to retain or find personally meaningful activities and ensure that they have access to supportive factors in the environment despite disruptions in their ordinary routines.

In summary, the applicability of available psychological treatments acknowledged to have strong research support in the clinical psychology literature such as BA should be considered when elite athletes suffer from mental health issues. However, to work proactively whenever possible is preferable to treating clinical conditions that have already developed. In line with the aim of the present case report, researchers and practitioners working in the field of elite sports are encouraged to disseminate applied knowledge about evidence-based interventions that successfully can be used with elite athletes for preventive purposes as well 


\section{APPLYING BEHAVIORAL ACTIVATION IN ELITE SPORTS}

as for the treatment of already developed clinical conditions. By doing so, a more substantial and well-informed scientific and applied knowledge base can be continually built, increasing the possibility of providing optimal support to promote the health and well-being of elite athletes both during and after their sports careers.

\section{References}

American Psychiatric Association (2013a). Diagnostic and statistical manual of mental disorders (5th ed.). Retrieved from https://doi.org/10.1176/appi.books.9780890425596

American Psychiatric Association (2013b). DSM-5 Self-Rated Level 1 Cross-Cutting Symptom Measure - Adult. Retrieved from https://www.psychiatry.org/psychiatrists/practice/dsm/educationalresources/assessment-measures

American Psychological Association Division 12 (2020). Diagnosis: Depression. Retrieved from https://www.div12.org/diagnosis/depression/

Appaneal, R. N., Levine, B. R., Perna, F. M., \& Roh, J. L. (2009). Measuring post-injury depression among male and female competitive athletes. Journal of Sport and Exercise Psychology, 31(1), 60-76. doi: 10.1123/jsep.31.1.60

Barlow, D. H. (2014). Clinical handbook of psychological disorders. A step-by-step treatment manual (5th ed.). New York: Guilford Publications.

Beard, J. I. L., \& Delgadillo, J. (2019). Early response to psychological therapy as a predictor of depression and anxiety treatment outcomes: A systematic review and meta-analysis. Depression and Anxiety, 36(9), 866-878. doi: 10.1002/da.22931

Beable, S., Fulcher, M., Lee, A.C., \& Hamilton, B. (2017). SHARPSports mental health awareness research project: Prevalence and risk factors of depressive symptoms and life 


\section{APPLYING BEHAVIORAL ACTIVATION IN ELITE SPORTS}

stress in elite athletes. Journal of Science and Medicine in Sport, 20(12), 1047-1052. doi: 10.1016/j.jsams.2017.04.018

Beck, A. T. (2019). A 60-year evolution of cognitive theory and therapy. Perspectives on Psychological Science, 14(1), 16-20. doi: 10.1177/1745691618804187

Brown, C. J., Webb, T. L., Robinson, M. A., \& Cotgreave, R. (2019). Athletes’ retirement from elite sport: A qualitative study of parents and partners' experiences. Psychology of Sport and Exercise, 40, 51-60. doi: 10.1016/j.psychsport.2018.09.005

Butler, G., Fennell, M., \& Hackmann, A. (2008). Cognitive-behavioral therapy for anxiety disorders: Mastering clinical challenges. New York: Guilford Publications.

Corrie, S., Townend, M., \& Cockx, A. (Eds.) (2015). Assessment and case formulation in cognitive behavioral therapy. London: SAGE.

Dimidjian, S., Barrera, M. Jr., Martell, C., Munoz, R. F., \& Lewinsohn, P. M. (2011). The origins and current status of BA treatments for depression. Annual Review of Clinical Psychology, 7, 1-38. doi: 10.1146/annurev-clinpsy-032210-104535

Dimidjian S, Hollon, S. D., Dobson, K. S., Schmaling, K. B., Kohlenberg, R. J., Addis, M. E., ... Jacobson, N. S. (2006). Randomized trial of behavioral activation, cognitive therapy, and antidepressant medication in the acute treatment of adults with major depression. Journal of Consulting and Clinical Psychology, 74(4), 658-670. doi: 10.1037/0022-006X.74.4.658

Doherty, S., Hannigan, B., \& Campbell, M.J. (2016). The experience of depression during the careers of elite male athletes. Frontiers in Psychology, 7:1069. doi:

10.3389/fpsyg.2016.01069 


\section{APPLYING BEHAVIORAL ACTIVATION IN ELITE SPORTS}

Eggleston, D., Hawkins, L. G., \& Fife, S. T. (2019). As the lights fade: A grounded theory of male professional athletes' decision-making and transition to retirement. Journal of Applied Sport Psychology. Advance online publication. doi:

$10.1080 / 10413200.2019 .1626514$

Forsell, E., Bendix, M, Holländare, F, von Schultz, B. S., Nasielle, J., Blomdahl-Wetterholm, M., ... Kaldo, V. (2019). Internet delivered cognitive behavior therapy for antenatal depression: A randomised controlled trial. Journal of Affective Disorders, 221, 56-64. doi: 10.1016/j.jad.2017.06.013

Golding, L., Gillingham, R.G., \& Perera, N.K.P. (2020). The prevalence of depressive symptoms in high-performance athletes: a systematic review. The Physician and Sportsmedicine. Advance online publication. doi: 10.1080/00913847.2020.1713708

Gouttebarge, V., Castaldelli-Maia, J.M., Gorczynski, P., Hainline, B., Hitchcock, M.E., Kerkhoffs, G.M., ... Reardon, C.L. (2019). Occurrence of mental health symptoms and disorders in current and former elite athletes: a systematic review and meta-analysis. British Journal of Sports Medicine, 53(11), 700-707, doi: 10.1136/bjsports-2019100671

Hagen, E. H. (2011). Evolutionary theories of depression: A critical review. Canadian Journal of Psychiatry, 56(12), 716-726. doi: 10.1177/070674371105601203

Hammen, C. L. (2015). Stress and depression: old questions, new approaches. Current Opinion in Psychology, 4, 80-85. doi: 10.1016/j.copsyc.2014.12.024

Hayes, S. C., Strosahl, K., \& Wilson, K. G. (2012). Acceptance and commitment therapy: The process and practice of mindful change. New York: Guilford Publications. 


\section{APPLYING BEHAVIORAL ACTIVATION IN ELITE SPORTS}

Howells, K., \& Lucassen, M. (2018). 'Post-Olympic blues' - the diminution of celebrity in Olympic athletes. Psychology of Sport and Exercise, 37, 67-78. doi: 10.1016/j.psychsport.2018.04.008

Jacobson, N. S., Dobson, K. S., Truax, P. A., Addis, M. E., Koerner, K., Gollan, J. K., ...Prince, S.E. (1996). A component analysis of cognitive-behavioral treatment for depression. Journal of Consulting and Clinical Psychology, 64(2), 295-304. doi: 10.1037//0022-006x.64.2.295

Johnsen, T. J., \& Friborg, O. (2015). The effects of cognitive-behavioral therapy as an antidepressive treatment is falling: A meta-analysis. Psychological Bulletin, 141(4), 747768. doi: 10.1037/bul0000015

Knights, S., Sherry, E., \& Ruddock-Hudson, M. (2016). Investigating elite end-of-athleticcareer transition: A systematic review. Journal of Applied Sport Psychology, 28(3), 291308. doi: 10.1080/10413200.2015.1128992

Kuyken, W., Padesky, C. A. \& Dudley, R. (2011). Collaborative case conceptualization. Working effectively with clients in cognitive-behavioral therapy. New York: Guilford Publications.

Lavallee, D., Gordon, S., \& Grove, J. R. (1997). Retirement from sport and the loss of athletic identity. Journal of Personal \& Interpersonal Loss, 2(2), 129-147. doi: $10.1080 / 10811449708414411$

Lebrun, F., MacNamara, A., Rodgers, S., \& Collins, D. (2018). Learning from elite athletes’ experiences of depression. Frontiers in Psychology, 9:2062. doi: 10.3389/fpsyg.2018.02062

Lindner, P., Frykheden, O., Forsström, D., Andersson, E., Ljótsson, B., Hedman, E., ... Carlbring, P. (2016). The Brunnsviken Brief Quality of Life Scale (BBQ): Development 


\section{APPLYING BEHAVIORAL ACTIVATION IN ELITE SPORTS}

and psychometric evaluation. Cognitive Behaviour Therapy, 45(3), 182-195. doi: 10.1080/16506073.2016.1143526

Lundqvist, C., \& Gustafsson, H. (2020). Psychological support for injured elite athletes: Experiences and reflections from an applied perspective. In A. Ivarsson \& U. Johnson (Eds.), Psychological bases for sport injuries (4th ed.) (pp.281-297). West Virginia: Fit Publishing.

Lutz, W., Stulz, N., \& Köck, K. (2009). Patterns of early change and their relationship to outcome and follow-up among patients with major depressive disorders. Journal of Affective Disorders, 118(1), 60-68. doi: 10.1016/j.jad.2009.01.019

Maj, M. (2011). When does depression become a mental disorder. The British Journal of Psychiatry, 199, 85-86. doi: 10.1192/bjp.bp.110.089094

Martell, C. R. (2013). Misconceptions and misunderstandings of behavioral activation: Perspectives from a major proponent. Psychologia, 56, 131-137. doi: 10.2117/psysoc.2013.131

Martell, C. R. (2018). Behavioral activation. In S.C. Hayes \& S.G. Hoffman (Eds.), Processbased CBT: The science and core clinical competencies of cognitive behavioral therapy (pp. 299-208). Oakland: New Harbinger Publications, Inc.

Martell, C. R., Addis, M. E., Jacobson, N. S. (2001). Depression in context: Strategies for guided action. New York: Norton.

Martell, C. R., Dimidjian, S., Herman-Dunn, R., Lewinsohn, P. M., \& Herman-Dunn, R. (2010). Behavioral activation for depression: A clinican's guide. New York: Guilford Publications. 


\section{APPLYING BEHAVIORAL ACTIVATION IN ELITE SPORTS}

Martin, L. A., Fogarty, G. J., \& Albion, M. J. (2013). Changes in athletic identity and life satisfaction of elite athletes as a function of retirement status. Journal of Applied Sport Psychology, 26(1), 96-110. doi: 10.1080/10413200.2013.798371

Masterson, C., Ekers, D., Gilbody, S., Richards, D., Toner-Clewes, B., \& McMillan, D. (2014). Sudden gains in behavioral activation for depression. Behaviour Research and Therapy, 60, 34-38. doi: 10.1016/j.brat.2014.06.008

Montgomery, S. A., \& Åsberg, M. (1979). A new depression scale designed to be sensitive to change. British Journal of Psychiatry, 134, 382-389. doi: 10.1192/bjp.134.4.382

National Institute for Health \& Clinical Excellence (2010). Depression. The Treatment and management of depression in adults (updated edition). Leicester: British Psychological Society.

Nixdorf, I., Frank, R., \& Beckmann, J. (2015). An explorative study on major stressors and its connection to depression and chronic stress among German elite athletes. Advances in Physical Education, 5(4), 255-262. doi:10.4236/ape.2015.54030

Osorno, J., Svanström, L., \& Beskow, J (Eds.) (2010). Community suicide prevention (2 ${ }^{\text {nd }}$ ed). Stockholm: Karolinska Institute.

Paris, J. (2015). The intelligent clinician's guide to DSM-5® (2nd ed.). New York: Oxford University Press.

Park, S., Lavallee, D., \& Tod, D. (2013). Athlete’s career transition out of sport: a systematic review. International Review of Sport and Exercise Psychology, 6(1), 22-53. doi: 10.1080/1750984X.2012.687053 


\section{APPLYING BEHAVIORAL ACTIVATION IN ELITE SPORTS}

Persons, J. B. \& Tompkins, M. A. (2006). Cognitive-behavioral case formulation. In Eells, T. D. (Ed.). Handbook of psychotherapy case formulation (2nd ed., pp. 290-316). New York: Guilford publications.

Sanders, G., \& Stevinson, C. (2017). Association between retirement reasons, chronic pain, athletic identity, and depressive symptoms among former professional footballers. European Journal of Sport Science, 17(10), 1311-1318. doi:

10.1080/17461391.2017.1371795

Singla, D. R., Hollon, S. D., Fairburn, C. G., Dimidjian, S., \& Patel, V. (2019). The roles of early response and sudden gains on depression outcomes: Findings from a randomized controlled trial of behavioral activation in Goa, India. Clinical Psychological Science, 7(4), 768-777. doi: 10.1177/2167702619825860

Spitzer, R. L., Kroenke, K., Williams, J. W., \& Löwe, B. (2006). A brief measure for assessing generalized anxiety disorder: The GAD-7. Archives Of Internal Medicine, 166(10), 1092-1097. doi: 10.1001/archinte.166.10.1092

Stambulova, N., Alfermann, D., Statler, T., \& Coté, J. (2009). ISSP Position stand: career development and transitions of athletes. International Journal of Sport and Exercise Psychology, 7, 395-412. doi: 10.1080/1612197X.2009.9671916

Stephan, Y., Bilard, J., Ninot, G., \& Deligniéres, D. (2003). Repercussion of transition out of elite sport on subjective well-being: A one-year study. Journal of Applied Sport Psychology, 15(4), 354-371. doi: 10.1080/714044202

Ströhle, A. (2019). Sports psychiatry: mental health and mental disorders in athletes and exercise treatment of mental disorders. European Archives of Psychiatry and Clinical Neuroscience, 269(5), 485-498. doi: 10.1007/s00406-018-0891-5 


\section{APPLYING BEHAVIORAL ACTIVATION IN ELITE SPORTS}

Sundel, M., \& Sundel, S. S. (2017). Behavior change in the human services. Behavioral and cognitive principles and applications ( $6^{\text {th }}$ ed.). Thousands Oak, CA: Sage Publications, Inc.

Svanborg, P., \& Åsberg, M. (2001). A comparison between the Beck Depression Inventory (BDI) and the self-rating version of the Montgomery Asberg Depression Rating Scale (MADRS). Journal of Affective Disorders, 64(2-3), 203-216. doi: 10.1016/s01650327(00)00242-1

Tang, T. Z., DuRubeis, R. J., Hollon, S. D., Amsterdam, J. D., \& Shelton, R. C. (2007). Sudden gains in cognitive therapy of depression and depression relapse/recurrence. Journal of Consulting and Clinical Psychology, 75(3), 404-408. doi: 10.1037/0022006X.75.3.404

Torregrosa, M., Ramis, Y., Pallarés, S., Azócar, F., \& Selva, C. (2015). Olympic athletes back to retirement: A qualitative longitudinal study. Psychology of Sport and Exercise, 21, 50-56. doi: 10.1016/j.psychsport.2015.03.003

Wakefield, J. S. (2015). DSM-5, psychiatric epidemiology and the false positives problem. Epidemiology and Psychiatric Sciences, 24(3), 188-196. doi: $10.1017 / \mathrm{S} 2045796015000116$

Wakefield, J. S., \& Schmitz, M. F. (2013). When does depression become a disorder? Using recurrence rates to evaluate the validity of proposed changes in major depression diagnostic threshold. World Psychiatry, 12(1), 44-52. doi: 10.1002/wps.20015

Wakefield, J. S., Smithz, M. F., \& Baer, J. C. (2010). Does the DSM-IV clinical significance criterion for major depression reduce false positives? Evidence from the national comorbidity survey replication. American Journal of Psychiatry, 167(3), 298-304. doi: 10.1176/appi.ajp.2009.09040553 


\section{APPLYING BEHAVIORAL ACTIVATION IN ELITE SPORTS}

Waltman, S. H., Creed, T. A., \& Beck, A. T. (2016). Are the effects of cognitive behavior therapy for depression falling? Review and critique of the evidence. Clinical Psychology: Science and Practice, 23(2), 113-122. doi: 10.1111/cpsp.12152

Whiteford, H. A., Harris, M. G., McKeon, G., Baxter, A., Pennell, C., \& Wang, J. (2013). Estimating remission from untreated major depression: a systematic review and metaanalysis. Psychological Medicine, 43(8), 1569-1585. doi: 10.1017/S0033291712001717

Wolanin, A., Gross, M., \& Hong, E. (2015). Depression in athletes: Prevalence and risk factors. Current Sports Medicine Reports, 14(1), 56-60. doi:10.1249/JSR.0000000000000123

Wylleman, P., Alfermann, D., \& Lavallee, D. (2004). Career transitions in sport: European perspectives. Psychology of Sport and Exercise, 5(1), 7-20. doi: 10.1016/S14690292(02)00049-3 
Table 1.

Description of self-rating scales and clinical guidelines for interpretation of scores.

\begin{tabular}{|c|c|c|}
\hline Scale & Content & Guidelines for clinical evaluation \\
\hline $\begin{array}{l}\text { MADRS-S } \\
\text { (9 items) }\end{array}$ & Depressive symptoms & $\begin{array}{l}\text { Not published. General Swedish clinical guidelines suggest } \\
\text { indications of: (a) mild depression =13-19; (b) moderate } \\
\text { depression = 20-34; (c) severe depression = 35-54 (e.g., } \\
\text { Forsell et al., 2017). }\end{array}$ \\
\hline $\begin{array}{l}\text { GAD-7 } \\
\text { (7 items) }\end{array}$ & Generalized Anxiety/Anxiety Symptoms & $\begin{array}{l}\text { Cut-off scores: Moderate anxiety }=10 \text {; Severe anxiety }=15 \\
\text { (Spitzer et al., 2006). }\end{array}$ \\
\hline $\begin{array}{l}\text { BBQ } \\
\text { (12 items) }\end{array}$ & Quality-of-life & $\begin{array}{l}\text { Non-clinical sample: } M=60.12(S D=16.01) \text {; Clinical } \\
\text { sample: } M=38.74(S D=17.23) \text { (Lindner et al., 2016). }\end{array}$ \\
\hline DSM-5 Self- & Various psychiatric conditions (DSM-5): Depression, anger, & Follow-up should be performed if scores $\geq 2$ (i.e., mild), \\
\hline Rated & mania, anxiety, somatic symptoms, suicidal ideation, psychosis, & except for scores related to substance use, suicidal ideation, \\
\hline $\begin{array}{l}\text { CCSM } \\
\text { (23 items) }\end{array}$ & $\begin{array}{l}\text { sleep problems, memory, repetitive thoughts and behaviors, } \\
\text { dissociation, personality functioning, substance use }\end{array}$ & $\begin{array}{l}\text { and psychosis, where follow-up is recommended for all } \\
\text { scores > } 0 \text { (American Psychiatric Association, 2013b) }\end{array}$ \\
\hline
\end{tabular}


Table 2.

Foa's self-ratings of progress related to individual treatment goals at sessions 1 and 4 .

Individual treatment goals Self-rating scale:

$$
0=\text { "not at all” to } 10=\text { "brilliant" }
$$

Rating session $1 \quad$ Rating session 4

Schedule my days so there is room for spontaneity (not 0

crowded days) and be able to change planning as needed

Meet another person every day, shift focus outwards (away

0

from rumination)

Tune into my life in a way that is balanced based on what I

value as important in my life 
APPLYING BEHAVIORAL ACTIVATION IN ELITE SPORTS

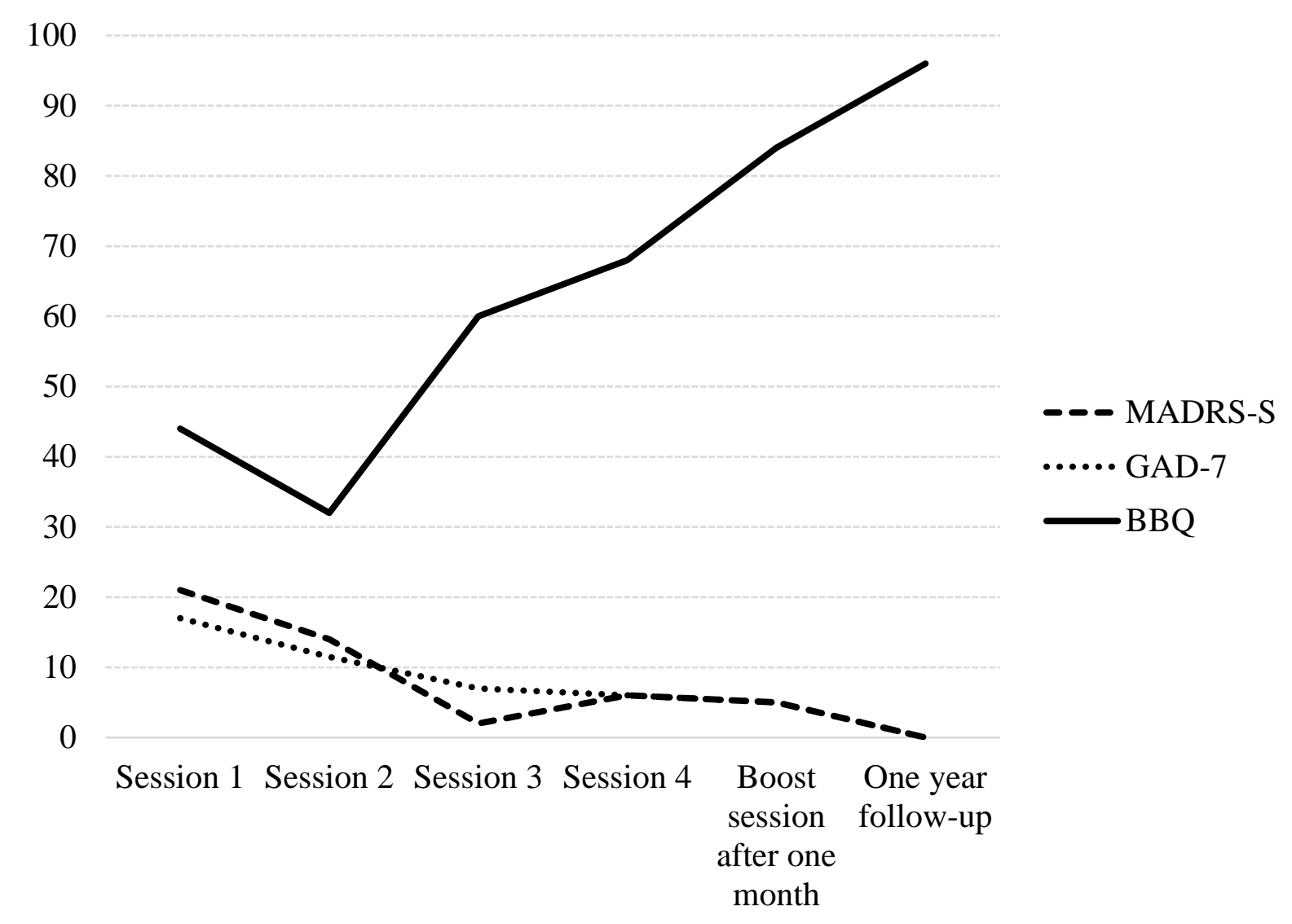

Figure 1.

The athlete's self-rated scores of depression (MADRS-S), anxiety (GAD-7) and quality-of-life (BBQ) performed once a week (session 1 to session 4), after one month (boost session) and one year follow-up. 